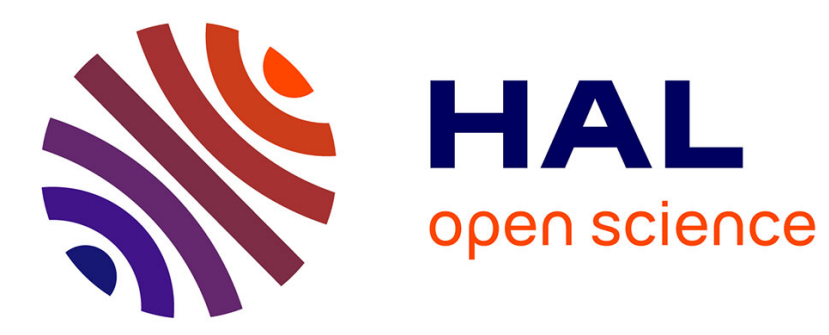

\title{
Internal model of gravity influences configural body processing
}

Julien Barra, Patrice Senot, Laurent Auclair

\section{To cite this version:}

Julien Barra, Patrice Senot, Laurent Auclair. Internal model of gravity influences configural body processing. Cognition, 2017, 158, pp.208 - 214. 10.1016/j.cognition.2016.10.018 . hal-01568948

\section{HAL Id: hal-01568948 \\ https://hal.science/hal-01568948}

Submitted on 26 Jul 2017

HAL is a multi-disciplinary open access archive for the deposit and dissemination of scientific research documents, whether they are published or not. The documents may come from teaching and research institutions in France or abroad, or from public or private research centers.
L'archive ouverte pluridisciplinaire HAL, est destinée au dépôt et à la diffusion de documents scientifiques de niveau recherche, publiés ou non, émanant des établissements d'enseignement et de recherche français ou étrangers, des laboratoires publics ou privés. 
Original Articles

\title{
Internal model of gravity influences configural body processing
}

\author{
Julien Barra ${ }^{\mathrm{a}, \mathrm{b}, *}$, Patrice Senot ${ }^{\mathrm{a}}$, Laurent Auclair ${ }^{\mathrm{c}}$ \\ a Laboratoire Vision Action Cognition EA7326, Institut de Psychologie, Université Paris Descartes, France \\ ${ }^{\mathrm{b}}$ Laboratoire de Psychologie et NeuroCognition (UMR 5105), Université de Savoie Mont Blanc, F-7300 Chambéry, France \\ ${ }^{\mathrm{c}}$ Institut de Psychologie, Université Paris Descartes, France
}

\section{A R T I C L E I N F O}

\section{Article history:}

Received 15 January 2016

Revised 18 October 2016

Accepted 27 October 2016

Available online 12 November 2016

\section{Keywords:}

Body inversion effect

Posture

Graviception

Configural process

Embodiment

\begin{abstract}
A B S T R A C T
Human bodies are processed by a configural processing mechanism. Evidence supporting this claim is the body inversion effect, in which inversion impairs recognition of bodies more than other objects. Biomechanical configuration, as well as both visual and embodied expertise, has been demonstrated to play an important role in this effect. Nevertheless, the important factor of body inversion effect may also be linked to gravity orientation since gravity is one of the most fundamental constraints of our biology, behavior, and perception on Earth. The visual presentation of an inverted body in a typical body inversion paradigm turns the observed body upside down but also inverts the implicit direction of visual gravity in the scene. The orientation of visual gravity is then in conflict with the direction of actual gravity and may influence configural processing. To test this hypothesis, we dissociated the orientations of the body and of visual gravity by manipulating body posture. In a pretest we showed that it was possible to turn an avatar upside down (inversion relative to retinal coordinates) without inverting the orientation of visual gravity when the avatar stands on his/her hands. We compared the inversion effect in typical conditions (with gravity conflict when the avatar is upside down) to the inversion effect in conditions with no conflict between visual and physical gravity.

The results of our experiment revealed that the inversion effect, as measured by both error rate and reaction time, was strongly reduced when there was no gravity conflict. Our results suggest that when an observed body is upside down (inversion relative to participants' retinal coordinates) but the orientation of visual gravity is not, configural processing of bodies might still be possible. In this paper, we discuss the implications of an internal model of gravity in the configural processing of observed bodies.
\end{abstract}

(c) 2016 Elsevier B.V. All rights reserved.

\section{Introduction}

The perception and recognition of actions, moods or intentions of other people are important skills for social interaction and communication. Human faces and bodies provide a particularly rich source of visual information in support of these abilities. Bodies and faces have a peculiar status for the brain since it constitutes specific visual objects that could involve a specific configural processing mechanism in non-expert subjects (Brandman \& Yovel, 2010; Brandman \& Yovel, 2016; Carey, De Schonen, \& Ellis, 1992; Carey \& Diamond, 1994; Diamond \& Carey, 1986; Leder \& Bruce, 2000; Reed, Nyberg, \& Grubb, 2012; Reed, Stone, Bozova, \& Tanaka, 2003; Reed, Stone, Grubb, \& McGoldrick, 2006; Rossion \& Gauthier, 2002; Yin, 1969; Zhou, Zhang, Liu, Yang, \& Qu, 2010).

* Corresponding author at: Laboratoire de Psychologie et NeuroCognition (UMR 5105), UFR LLSH, Université de Savoie Mont Blanc, Domaine Universitaire de JacobBellecombette, B.P. 110473011 Chambéry Cedex, France.

E-mail address: julien.barra@univ-savoie.fr (J. Barra).
Configural processing is defined by Reed et al. (2006) as any phenomenon that involves perceiving spatial relations among the features of stimuli such as faces or bodies. Many authors have demonstrated that strong inversion effects in which recognition of faces (Carey \& Diamond, 1994; Diamond \& Carey, 1986; Leder \& Bruce, 2000; Rossion and Gauthier, 2002; Yin, 1969) or of human bodies (Brandman \& Yovel, 2010; Brandman \& Yovel, 2016; Reed et al., 2003, 2006, 2012) is disrupted when turned upside down. Conversely, little or no inversion effect was reported for other stimuli such as animals or houses (Carey et al., 1992; Reed et al., 2003; Yin, 1969; Zhou et al., 2010). It has been suggested that inversion effects indicate configural processing. Indeed, turning familiar objects upside down disrupts the viewer's ability to rapidly process the interrelations between the parts of an object, at a configural level (Brandman \& Yovel, 2010, 2016; Maurer, Le Grand, \& Mondloch, 2002; Reed et al., 2003; Rhodes, Brake, \& Atkinson, 1993).

Although body and face produce comparable body inversion effects they may be processed by different configural mechanisms. 
Indeed, body inversion effects involve distinct, specific bases from the face inversion effects (Brandman \& Yovel, 2010; Brandman \& Yovel, 2016; Rossion \& Gauthier, 2002). Furthermore, evidence of dissociation of face and body configural processing mechanisms has recently been obtained in prosopagnosic patients (Susilo, Yovel, Barton, \& Duchaine, 2013) who exhibited normal inversion effects for bodies despite face perception impairment.

Properties of the specific body processing were investigated using the size of the inversion effect as empirical indicator of change in configural processing. A reduced inversion effect was reported when visual stimuli violated human body biomechanics (Pinto \& Shiffrar, 1999; Ramm, Cummins, \& Slaughter, 2010; Reed et al., 2003, 2006, 2012) as well as in unfamiliar postures (Reed et al., 2012). Reed et al. (2012) suggested that biomechanical configuration as well as both visual and embodied expertise play an important role in body processing. Nevertheless, an important factor of body inversion effect may also be linked to visual information regarding gravity orientation. The visual presentation of an inverted body (inversion relative to participants' retinal coordinates) in typical body inversion paradigm (Reed et al., 2003) turns the stimulus upside down (body presented with the head down and the feet up) but also "up" and "down" directions of the surroundings (implicit visual gravity of the scene). Indeed, the inversion of a body stimulus induces the inversion of visual gravity orientation through the postural configuration of the body segments. The body seems to be standing on his/her feet as if it was drawn toward the ceiling by visual gravity. In this condition, the inversion of visual body orientation creates a conflict between the actual direction of gravity and the orientation of visual gravity extracted from the posture of the presented body. Astronauts are familiar with such a conflict as they experience visual reorientation illusion and motion sickness when viewing a crewmember floating upside down in their environment (Oman, Lichtenberg, Money, \& McCoy, 1986).

Gravity is one of the most fundamental constraints of our biology, behavior, and perception on Earth. It plays a role in structuring not only our world but also how we perceive it and act on it. Human beings construct an internal model of gravity leading to a sense of verticality and relate "up" and "down" directions in order to spatially orient themselves and the world (Barra \& Pérennou, 2013; Barra et al., 2010; Jenkin, Dyde, Jenkin, Howard, \& Harris, 2003). This internal model represents a general neural process used by the brain to integrate information from disparate sensory modalities, combine efferent and afferent information but also to resolve sensory ambiguity (Merfeld, Zupan, \& Peterka, 1999). In the framework of the body inversion paradigm, the conflict between visual and actual gravity creates sensory ambiguity that integration of internal model processing resolves to maintain coherent overall orientation (Howard \& Hu, 2001). This graviceptive processing may affect configural body mechanisms. To test this hypothesis, we dissociated the orientations of body and visual gravity so that body orientation could be inverted while visual gravity remained congruent with actual gravity. It is the case when someone does a handstand, for example. In this posture, body orientation is inverted relative to participants' retinal coordinates (the head is down while the feet are up) but the orientation of visual gravity remains congruent with the actual one. In our experiment, the only visual gravity available was from body postures being viewed. We predicted that the body inversion effect would be reduced when body orientation was inverted without conflict of gravity orientation. Before the experimental comparison of inversion effect in typical conditions and in conditions without gravity conflict, we conducted a pretest to investigate whether it was possible to turn an avatar upside down relative to participants' retinal coordinates while visual gravity orientation was kept aligned with the actual one.

\section{Pre-test}

\subsection{Participants}

Twenty-two volunteers (10 males and 12 females, $25 \pm 2$ years old), naive to the goals of the experiment, participated in stimuli pretest. All had normal or corrected-to-normal vision (subjects who wore glasses or contact lenses did so during the experiment), and none had any known visual, neurological, vestibular or oculomotor impairments. All subjects were right-handed (according to the Edinburgh inventory) and gave informed consent.

\subsection{Pretest material}

The body stimuli were created according to the paradigm developed by Reed et al. (2003). The stimuli were $14 \mathrm{~cm} \times 10 \mathrm{~cm}$ three-dimensional male and female figures created using Poser Professional $10^{\mathrm{TM}}$ (e frontier). The arms and legs of each figure were positioned to create new poses that were visually distinguishable from one another, had no meaning, and could not be easily labeled. Visual gravity orientation was manipulated (Fig. 1) by modulating body postures. We created 16 stimuli with upright avatars standing on their feet and 16 stimuli with upside down avatars standing on their hands relative to retinal coordinates. Half were males and half were females. All poses were bio-mechanically possible in terms of configuration of the body segments. For example, extension of the forearm was limited to biological range. Furthermore, the poses were plausible in terms of balance per se - independently of the orientation of the image - with one or two hands or feet in contact with an invisible floor. The poses were asymmetrical with respect to both vertical and horizontal axes.

\subsection{Pretest procedure}

In our experiment, we aimed at manipulating the orientation of visual gravity by modulating avatar postures. In order to check that modulating avatar posture impacted visual gravity orientation, we asked the 22 participants to indicate the direction that a ball released by the avatar would take according to gravity within the picture (32 body-stimulus pairs). All the avatars were centered within the images and all the images were centered within the screen. The participants had to indicate the direction that a ball released by the avatar would take according to gravity within the picture. They pressed the "Up Arrow" key if they considered that the direction of gravity was upward and the "Down Arrow" key if they considered that gravity was downward. Using E-prime 2.0, the 16 avatars standing on their feet (Fig. 1a) and the 16 avatars standing on their hands (Fig. 1d) were randomly presented in an upright position and in an inverted one $\left(180^{\circ}\right.$; Fig. $1 \mathrm{~b}$ and $\left.\mathrm{c}\right)$ in a block of 64 items. The block was repeated 3 times with a break between each. Each participant was seated $70 \mathrm{~cm}$ away from a 17-inch computer screen. Chair height was adjusted so that the participants' eyes were level with the center of the screen. In each trial, the stimulus was displayed for $250 \mathrm{~ms}$, followed by a blank screen until the participants responded. The participants had been informed that the direction of visual gravity could be upright or inverted (downward or upward). We measured the proportion of upward and downward responses to the different conditions of body orientation (upright or upside down relative to retinal coordinates) and postures (avatar standing on his/her feet or hands).

\subsection{Pretest results}

One sample- $t$ tests were used to test the proportion of downward response rates for the four experimental conditions against 

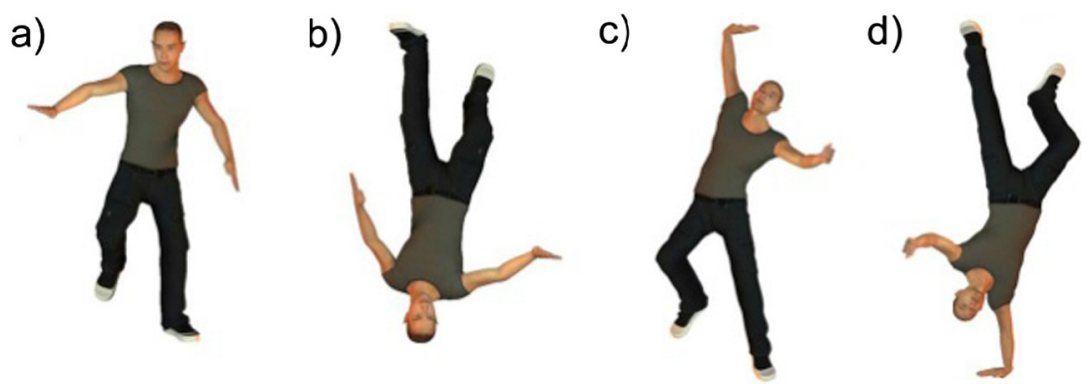

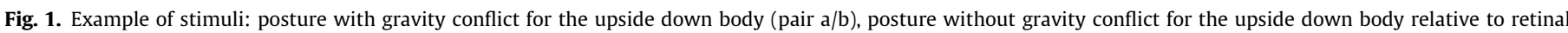
coordinates (pair $\mathrm{c} / \mathrm{d}$ ).

1. The threshold of statistical significance was set at 0.05 . The normality of data distributions was tested using Kolmogorov-Smirnov test. All distributions did not differ from normality (all $\mathrm{p}>0.05$ ).

The results (Fig. 2) showed that perceived gravity direction was downward for stimuli with upright avatars standing on their feet (Fig. $1 \mathrm{a} ; \mathrm{t}(21)=-1.45 ; \mathrm{p}=0.16 ; 95 \%$ confidence interval $[1 ; 0.98])$, stimuli with upside down avatars standing on their hands (Fig. $1 \mathrm{~d} ; \mathrm{t}(21)=-1.70 ; \mathrm{p}=0.10 ; 95 \%$ confidence interval $[1 ; 0.97])$ and stimuli with upright avatars standing on their hands (Fig. 1c; $\mathrm{t}(21)=-1.92 ; \mathrm{p}=0.07 ; 95 \%$ confidence interval $[1 ; 0.92]$ ). In the latter condition, the direction of visual gravity remained congruent with actual gravity (downward) while it corresponded to the inversion of a hand-standing avatar. In this condition, partic- ipants mainly reported the impression that the avatars were jumping and touching the ceiling. Furthermore, perceived gravity direction was upward for stimuli with upside down avatars standing on their feet (Fig. 1b; $\mathrm{t}(21)=-42.42 ; \mathrm{p}<0.001 ; 95 \%$ confidence interval $[0.18 ; 0.10])$.

Our results confirm that viewing bodies that have been inverted relative to participants' retinal coordinates not only turns the orientation of the body upside down, but can also invert the perceived direction of gravity. Furthermore, we showed that it was possible to turn the orientation of an avatar upside-down while keeping visual gravity orientation aligned with the actual one (Fig. 1d).

The results of the pretest validated our experimental stimuli and allowed measuring inversion effect both in typical conditions

perceived downward gravity perceived upward gravity

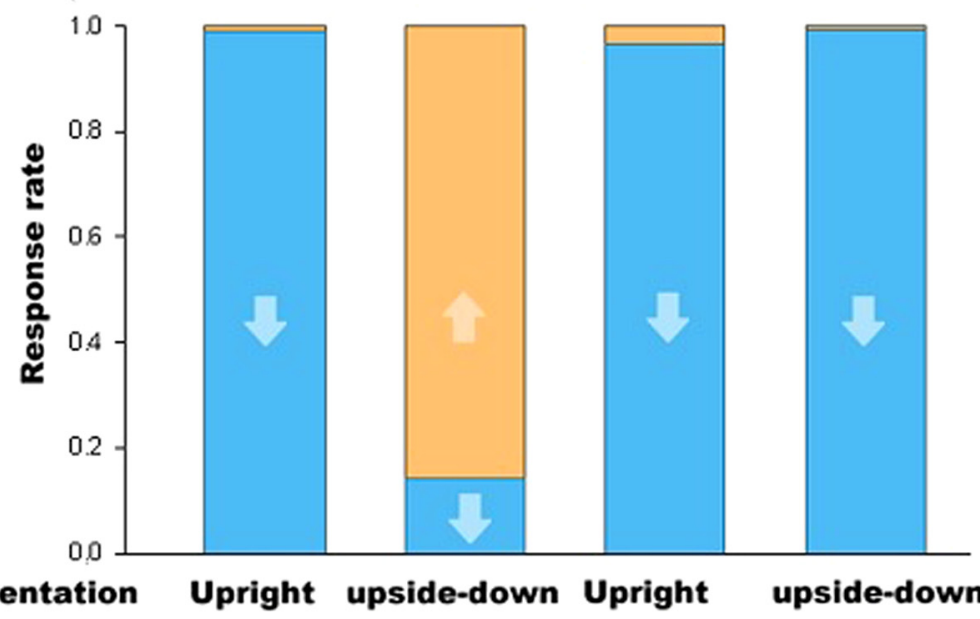

Body Orientation
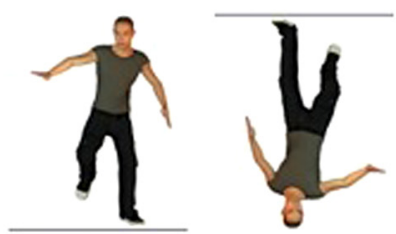

Actual gravity

Perceived visual gravity

Stimulus pairs' categoies
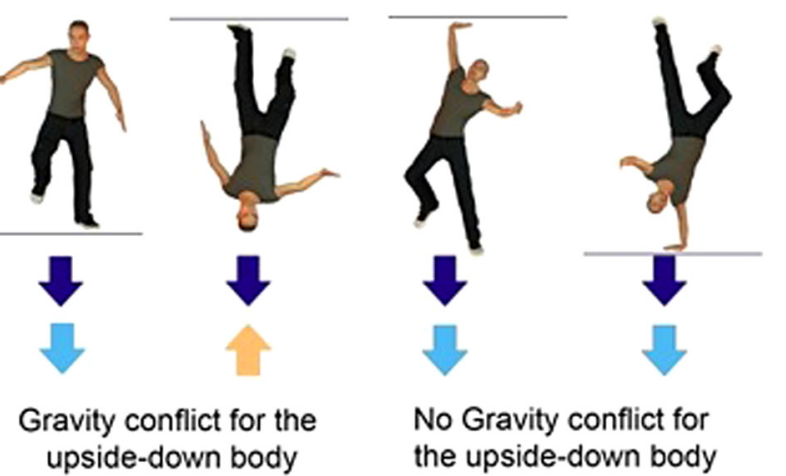

No Gravity conflict for the upside-down body

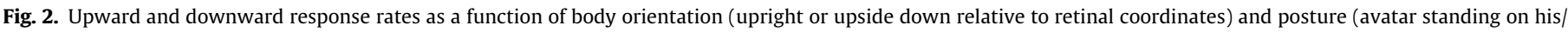
her feet or hands) 
(with gravity conflict when the avatar is upside down) and in conditions without gravity conflict.

\section{Experiment}

\subsection{Participants}

Twenty-two naive volunteers (10 males and 12 females, $22 \pm 3$ years old) participated in the experimental protocol. None of them had participated in the pretest. All had normal or corrected-to-normal vision (subjects who wore glasses or contact lenses did so during the experiment), and none had any known visual, neurological, vestibular or oculomotor impairments. All subjects were right-handed (according to the Edinburgh inventory) and gave informed consent. The objective of our study was to test the effect of gravity conflict on body inversion effect. Required sample size (22) was determined using G*power (Faul, Erdfelder, Lang, \& Buchner, 2007) based on the body inversion effect on reaction time reported by Reed et al. $(2003)(F(1.14)=10.8)$ with the following parameters: $\mathrm{F}$ effect size: 0.3 ; alpha error probability: 0.05 ; power: 0.95 ; number of measurements: 6 .

\subsection{Experimental material and procedure}

The 32 body stimuli selected in the pretest were used in the experiment. A distractor was constructed for each body stimulus by altering the position of two body parts: an arm or a leg of the figure was placed at a different angle or in a different position. All poses were biomechanically possible. In sum, there were 16 pairs of avatars standing on their feet and 16 pairs of avatars standing on their hands. Half of them were males and half of them were females.

Each participant was seated $70 \mathrm{~cm}$ away from a 17-in. computer screen. Head position was maintained with a chin rest. The experiment took place in the dark and the screen was placed in front of an empty wall to limit the possible influence of the visual surroundings. The participant was asked to determine whether the two body positions presented were the same or were different. In each trial, the first stimulus was displayed for $250 \mathrm{~ms}$, followed by a blank screen for 1000 ms. Finally, a second stimulus was displayed until the participant responded. The participant pressed the "E" key using the left index finger if the stimuli were the same and the " $O$ " key using their right index finger if the stimuli were different.

The 32 experimental stimuli were randomly presented in an upright position and in an inverted position relative to participants' retinal coordinates $\left(180^{\circ}\right)$ in a block of 64 items repeated six times. Each stimulus pair was presented 12 times, six times in an upright position and six times in an inverted position $\left(180^{\circ}\right)$. In half the trials, the two stimuli were identical, whereas in the other half, they were different. The experiment started with eight practice trials with four "identical" and four "different" stimuli, including some that were not in the experimental blocks. The entire session lasted about one hour. In all the trials, participants were asked to respond as fast and as accurately as possible. Response time (RT) and accuracy of the response were recorded.

\subsection{Data analysis}

Mean proportion error and RT were calculated for each condition and for each participant. For RT data, we analyzed only trials that corresponded to a correct response: $7468 \pm 506$ trials over 8448 (88.4\%). When reaction time was slower than $200 \mathrm{~ms}$ or when it deviated from the mean by more or by less than 3 standard deviations, the trial was excluded $(0.5 \%$ of the data). The normality of data distributions was tested using Kolmogorov-Smirnov test. No distributions differed from normality (all $p>0.05$ ).

The inversion effect was calculated by the subtraction of the error rate measured in upright orientation from the error rate in inverted orientation $\left(-180^{\circ}\right)$ for each pair. This was calculated for conditions with gravity conflict (b-a conditions in Fig. 1) and conditions without gravity conflict (d-c conditions in Fig. 1). The inversion effects were compared using Student's t-test. The threshold of statistical significance was set at 0.05 . When needed, a Bonferroni correction for multiple comparisons was used. In this case, the corrected threshold of statistical significance was $\alpha=0.025$ $(0.05 / 2)$

\subsection{Experimental results}

Analysis of error rates (Fig. 3) revealed that the inversion effect was strongly reduced when there was no conflict between visual and actual gravity compared to the conditions were there was a conflict of gravity $\left(t(21)=2.72 ; \mathrm{p}<0.02\right.$; partial eta $\left.{ }^{2}=0.26\right)$.

The inversion effects were decomposed with Student's $t$-test. Analysis revealed that in the conditions with upside down bodies, participants made more errors when gravity orientation was also inverted (gravity conflict, Fig. 1b) than when visual gravity was upright (Fig. 1d) $(\mathrm{t}(21)=3.87 ; \mathrm{p}<0.001$; partial eta $2=0.42)$. In contrast, we found no differences between the conditions with upright bodies (Fig. 1a and $\mathrm{c}$ ) $(\mathrm{t}(21)=0.35 ; \mathrm{p}=0.73$; partial eta2 $=0.006$ ).

The inversion effect was also computed on RT for conditions with gravity conflict (conditions b-a in Fig. 1) and conditions without gravity conflict (conditions d-c in Fig. 1). The normality of data distributions was tested using Kolmogorov-Smirnov test. No distributions differed from normality (all $p>0.05$ ). The inversion effects were compared using Student's $t$-tests. The threshold of statistical significance was set at 0.05 .

The reaction time results (Fig. 4) revealed that the inversion effect was also strongly reduced in the condition in which there was no gravity conflict compared to the conditions in which there was a gravity conflict $\left(\mathrm{t}(21)=2.87 ; \mathrm{p}<0.001\right.$; partial eta $\left.{ }^{2}=0.28\right)$. Analysis revealed that in conditions with upside down bodies relative to retinal coordinates, participants were slower when gravity orientation was also inverted (gravity conflict, Fig. 1b) than when visual gravity was upright relative to retinal coordinates (Fig. 1d) $\left(\mathrm{t}(21)=4.10 ; \mathrm{p}<0.001 ;\right.$ partial eta $\left.{ }^{2}=0.45\right)$. In contrast, we found

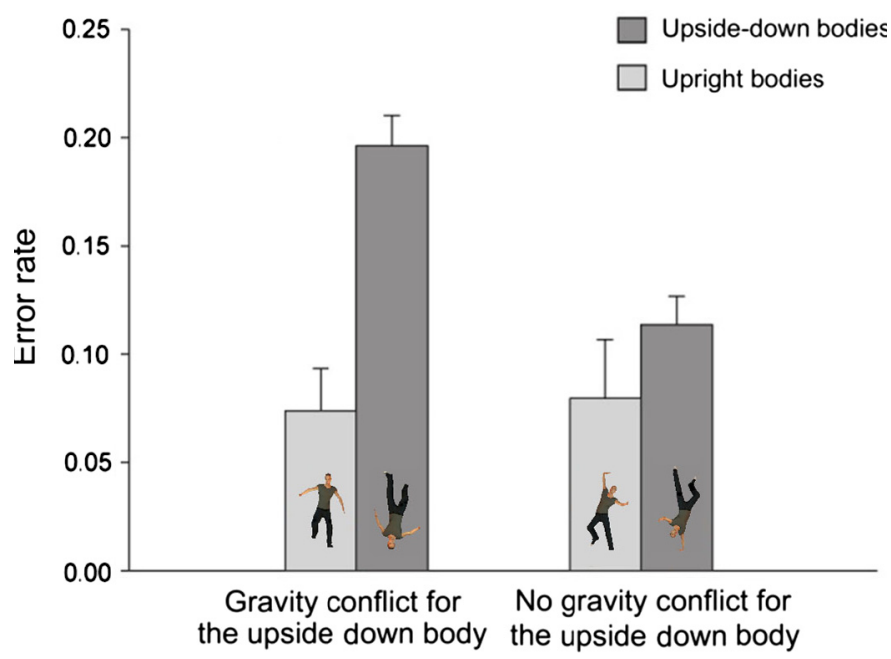

Fig. 3. Proportion of error for upright and upside down bodies relative to retinal coordinates as a function of the pairs of stimuli with or without gravity conflict. Error bars indicate the standard error of the mean. 


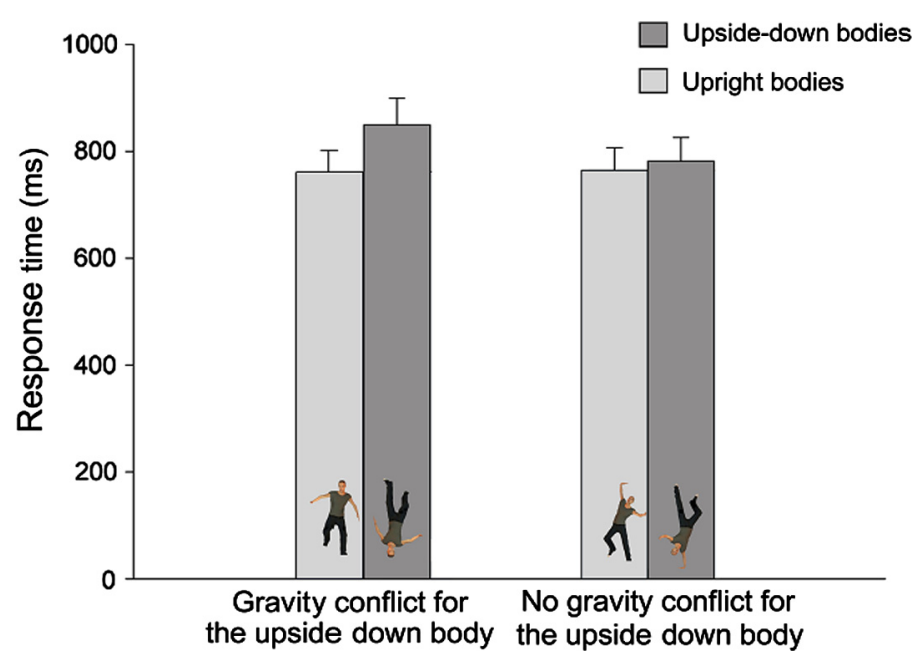

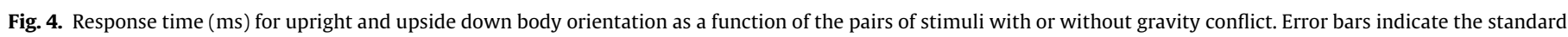
error of the mean.

no differences between the conditions with upright bodies (Fig. 1a and $c)\left(t(21)=0.13 ; p=0.89\right.$; partial eta $\left.{ }^{2}=0.001\right)$.

\section{Discussion}

The aim of our study was to test the possible influence of gravity conflict on the body inversion effect. To investigate the influence of visual gravity, we dissociated the orientations of visual gravity and of the body by manipulating body posture. Our objective was to create visual stimuli in which body orientation was inverted but gravity direction was not. The results of our pretest showed that a visual posture contains gravity information that can be extracted for a conscious decision of visual gravity orientation. These results confirmed the possible existence of gravity conflict in the classical inversion paradigm even if highly cognitive processes may have been involved in the pretest task. Similar potential highly cognitive processes might not have been involved in the experiment since the task was focused on visual gravity orientation within the image only in the pretest. Our pretest also demonstrated that gravity conflict can be solved by manipulating implicit visual gravity due to body posture. Nevertheless, participants' estimations of visual gravity orientation were theoretically incorrect in the condition where the avatar was doing a handstand and the image was presented upside down. This incorrect interpretation of visual gravity indicates that the implicit visual direction of gravity extracted from body posture cannot induce a conflict of gravity when the orientation of the observed body is upright in participants' retinal coordinates. The congruence of participant orientation, avatar orientation and actual gravity is probably strong enough to solve the potential conflict induced by manipulating implicit visual gravity.

The experiment took place in the dark and the screen was placed in front of an empty wall to limit the possible influence of the visual surroundings. Nevertheless -due to the screen glowthe edges of the screen were visible. The avatar's relationship to the edge of the screen may have influenced visual processing. Indeed, it can be suggested that the top and the bottom of the screen could be assimilated to floor or ceiling depending on experimental conditions. This influence may have been limited since position and orientation of the floor -suggested by avatar posture- were at least $3.25 \mathrm{~cm}$ from the edge and were presented in all conditions.

The results of our pretest allowed calculating inversion effect without gravity conflict where only the orientation of the avatar was inverted. We compared the inversion effect obtained without gravity conflict with the typical inversion effect in which both avatar and visual gravity orientation were inverted. Our results revealed that the inversion effect was strongly reduced (by about $70 \%$ ) when there was no gravity conflict for both error rate and reaction time. Analysis of the reduction of the body inversion effect in the condition without gravity conflict showed that it was due to a rapid, accurate processing of the upside down body. In the typical paradigm (condition with gravity conflict) the inversion effect was due to a slower, less accurate processing of upside down bodies than upright bodies (Reed et al., 2003) and is interpreted as a disruption of configural processing. Our results suggested that when a body is upside down relative to participants' retinal coordinates but is not in conflict with actual gravity, configural processing of bodies remains possible. Our results also demonstrate that the body inversion effect doesn't mainly rely on retinal coordinates. The implication of graviception in visual processing found in our study is congruent with previous results on face inversion reported by Lobmaier and Mast (2007). Indeed, the authors investigated the effect of participants' body orientation relative to gravity on face inversion effect. They demonstrated that face inversion effect is based mainly on the orientation of the face stimulus with respect to the retinal reference frame. Nevertheless, in head-down participants, the gravitational and retinal reference frames deviated substantially. Consequently, participants found it difficult to perceive the orientation of visual stimuli unambiguously. Our results suggest that the implication of graviception in body inversion effect is more pronounced than in face inversion effect. This might be explained by the fact that implicit gravity information on faces is relatively limited while extraction of gravity may be one of the properties of visual body processing.

Previous research had demonstrated that the familiarity of body postures (Reed et al., 2003, 2012; Rossion \& Gauthier, 2002), visual and embodied expertise (Reed et al., 2012) as well as the biomechanical limitations and possibilities of a human body (Reed et al., 2012; Shiffrar \& Freyd, 1990, 1993) contribute to the configural processing of visual bodies. The latter explanation is unlikely to account for our results since all the postures we used were biomechanically possible. Furthermore, despite the limited visual and embodied experience of inverted bodies and limited familiarity with people standing on their hands we reported rapid, accurate body processing when upside down avatars stood on their hands. We state that the existence of conflict of gravity direction 
between visual graviception and actual Earth acceleration may be a better explanation of our results.

Gravity is crucial information to orient our bodies as well as objects in space. It is also essential to maintain our posture (Bonan et al., 2007; Pérennou et al., 2014) or to plan action (Lopez, Bachofner, Mercier, \& Blanke, 2009; Rosenberg \& Angelaki, 2014; Zago, McIntyre, Senot, \& Lacquaniti, 2008). Nevertheless, there is no receptor dedicated only to graviception in the human body (Barra \& Pérennou, 2013). The brain uses all the information available through the perceptual systems to determine orientation and related "up" and "down" directions. In daily life, sensory information (vestibular, visual and proprio-somesthetic) is congruent but conflict can be observed after brain lesion, sensory deterioration or artificial manipulation (Barra, Pérennou, Thilo, Gresty, \& Bronstein, 2012; Howard \& Hu, 2001; Lopez et al., 2009; Preuss, Harris, \& Mast, 2013). The influence of visual information in graviception has been spectacularly demonstrated by Howard and Hu (2001) who showed that participants positioned in the middle of a room furnished with polarized objects had the illusion of being in a different position from their actual position (lying down, standing or upside down) when the visual room was rotated $\left(90^{\circ}\right.$ or $\left.180^{\circ}\right)$. In particular, they revealed that when both the room and participants' orientation were turned congruently upside down, $68 \%$ of the participants considered that gravity was aligned with the vision + body orientation while actual gravity direction was exactly the opposite. In this case, the resolution of sensory ambiguity involved a modification of sensory signal integration with a reduction of the weight of vestibular information. These processes may impact other perceptual mechanisms. In our experiment, the participants and the actual gravity orientations were congruent and may have constituted the main gravity orientation. In these conditions, the visual orientation of the inverted avatar standing on his/her feet was in conflict with overall gravity orientation and the weight of visual information may have been attenuated by the brain, leading to alteration of configural processing.

Furthermore, it can be postulated that the body representations used for body recognition involve a gravity component. According to Reed et al. (2003) the perception of a human posture might involve an active process in which the perceived body could be mapped onto the observer's body representation. This body representation which corresponds to the typical configural relations characterizing human bodies is thought to be extracted from two types of expertise: visual (acquired through viewing experience) or embodied (acquired through bodily experience, i.e., moving, positioning, and using one's body) expertise (Diamond \& Carey, 1986; Reed et al., 2012; Tanaka \& Gauthier, 1997). Our results suggest that body representations could involve an internal model of gravity built through visual and kinesthetic experiences. The representation of bodies might then be oriented according to a vertical representation since it was acquired by visual and embodied experiences which were dependent on and impacted by gravity. When visual gravity evoked by a posture is congruent with actual gravity or with an internal model of gravity, body representation might be used even if the body is upside down. Conversely, when the gravity visually evoked is inverted, it could be in conflict with the gravity component of body representation, leading to a disruption of the configural processes of body recognition.

Configural processing is used to refer to any phenomenon that involves perceiving spatial relations among the features of stimuli as faces or bodies (Reed et al., 2006). Leder and Bruce (2000) had developed a continuum of configural processing from first-order spatial relations (i.e., the forearm was attached to the arm, the arm was attached to the shoulder) to second-order configuration defined by interactive processing between body parts (any biomechanically possible position of the limbs and body as a whole). Our results confirmed that the second-order configuration is involved in body inversion. More interestingly, our results indicate that the second-order configuration is not limited to strict biomechanical properties of the body but also involves gravitational properties. Visual gravitation information may play a critical role in the perception of body biomechanics. This interpretation is compatible with neuroimaging studies that have shown that static body images activate not only object recognition systems but also parts of the motor planning system and movement perception system (Brandman \& Yovel, 2016). The implicit extraction of visual gravitational information from a body posture suggests that long-term representation of body configuration contains, not only information regarding the spatial organization of body parts in the context of a whole body, but also gravitational information. The body schema has been defined as a hierarchical topological representation that preserves the local relationship among body parts and provides a spatial map among body parts (Buxbaum \& Branch Coslett, 2001; Reed et al., 2006; Slaughter et al., 2004). Our present findings suggest that this body schema might integrate gravitational constraints via internal models of gravity.

\section{Disclosure}

The authors report no disclosures relevant to the manuscript.

\section{Source of funding}

No.

\section{Appendix A. Supplementary material}

Supplementary data associated with this article can be found, in the online version, at http://dx.doi.org/10.1016/j.cognition.2016. 10.018 .

\section{References}

Barra, J., Marquer, A., Roxane, J., Reymond, C., Metge, L., Chauvineau, V., \& Pérennou, D. (2010). Humans use internal models to construct and update a sense of verticality. Brain, 133, 3552-3563.

Barra, J., \& Pérennou, D. (2013). Is the sense of verticality vestibular? Clinical Neurophysiology, 43(3), 197-204.

Barra, J., Pérennou, D., Thilo, K. V., Gresty, M. A., \& Bronstein, A. M. (2012). The awareness of body orientation modulates the perception of visual vertical. Neuropsychologia, 50(10), 2492-2498.

Bonan, I. V., Hubeaux, K. Gellez-Leman, M. C. Guichard, J. P. Vicaut, E. \& Yelnik, A P. (2007). Influence of subjective visual vertical misperception on balance recovery after stroke. Journal of Neurology, Neurosurgery \& Psychiatry, 78(1), 49-55.

Brandman, T., \& Yovel, G. (2010). The body inversion effect is mediated by faceselective, not body-selective, mechanisms. The Journal of Neuroscience, 30(31), 10534-10540.

Brandman, T, \& Yovel, G. (2016). Bodies are represented as wholes rather than their sum of parts in the occipital-temporal cortex. Cerebral Cortex, 26(2), 530-543. 5.

Buxbaum, L. J., \& Branch Coslett, H. (2001). Specialised structural descriptions for human body parts: Evidence from autotopagnosia. Cognitive Neuropsychology, 18(4), 289-306.

Carey, S., De Schonen, S., \& Ellis, H. D. (1992). Becoming a face expert [and discussion]. Philosophical Transactions of the Royal Society B: Biological Sciences, 335(1273), 95-103.

Carey, S., \& Diamond, R. (1994). Are faces perceived as configurations more by adults than by children? Visual Cognition, 1(2-3), 253-274.

Diamond, R., \& Carey, S. (1986). Why faces are and are not special: An effect of expertise. Journal of Experimental Psychology: General, 115(2), 107.

Faul, F., Erdfelder, E., Lang, A.-G., \& Buchner, A. (2007). G*Power 3: A flexible statistical power analysis program for the social, behavioral, and biomedical sciences. Behavior Research Methods, 39, 175-191.

Howard, I. P., \& Hu, G. (2001). Visually induced reorientation illusions. PerceptionLondon, 30(5), 583-600.

Jenkin, H. L., Dyde, R. T., Jenkin, M. R., Howard, I. P., \& Harris, L. R. (2003). Relative role of visual and non-visual cues in determining the direction of "up": Experiments in the York tilted room facility. Journal of Vestibular Research, 13(4), 287-293. 
Leder, H., \& Bruce, V. (2000). When inverted faces are recognized: The role of configural information in face recognition. The Quarterly Journal of Experimental Psychology: Section A, 53(2), 513-536.

Lobmaier, J. S., \& Mast, F. (2007). The thatcher illusion: Rotating the viewer instead of the picture. Perception, 36, 537-546.

Lopez, C., Bachofner, C., Mercier, M., \& Blanke, O. (2009). Gravity and observer's body orientation influence the visual perception of human body postures. Journal of vision, 9(5), 1.

Maurer, D., Le Grand, R., \& Mondloch, C. J. (2002). The many faces of configural processing. Trends in Cognitive Sciences, 6(6), 255-260.

Merfeld, D. M., Zupan, L., \& Peterka, R. J. (1999). Humans use internal models to estimate gravity and linear acceleration. Nature, 398(6728), 615-618.

Oman, C. M., Lichtenberg, B. K., Money, K. E., \& McCoy, R. K. (1986). M.I.T./Canadian vestibular experiments on the Spacelab-1 mission: 4. Space motion sickness: Symptoms, stimuli, and predictability. Experimental Brain Research, 64(2), 316-334.

Pérennou, D., Piscicelli, C., Barbieri, G., Jaeger, M., Marquer, A., \& Barra, J. (2014). Measuring verticality perception after stroke: Why and how? Neurophysiologie Clinique/Clinical Neurophysiology, 44(1), 25-32.

Pinto, J., \& Shiffrar, M. (1999). Subconfigurations of the human form in the perception of biological motion displays. Acta Psychologica, 102(2), 293-318.

Preuss, N., Harris, L. R., \& Mast, F. W. (2013). Allocentric visual cues influence mental transformation of bodies. Journal of Vision, 13(12), 14.

Ramm, B. J., Cummins, T. D., \& Slaughter, V. (2010). Specifying the human body configuration. Visual Cognition, 18(6), 898-919.

Reed, C. L., Nyberg, A. A., \& Grubb, J. D. (2012). Contributions of visual and embodied expertise to body perception. Perception, 41, 436-446.

Reed, C. L., Stone, V. E., Bozova, S., \& Tanaka, J. (2003). The body-inversion effect. Psychological Science, 14(4), 302-308.
Reed, C. L., Stone, V. E., Grubb, J. D., \& McGoldrick, J. E. (2006). Turning configural processing upside down: Part and whole body postures. Journal of Experimental Psychology: Human Perception and Performance, 32(1), 73.

Rhodes, G., Brake, S., \& Atkinson, A. P. (1993). What's lost in inverted faces? Cognition, 47(1), 25-57.

Rosenberg, A., \& Angelaki, D. E. (2014). Gravity influences the visual representation of object tilt in parietal cortex. The Journal of Neuroscience, 34(43), $14170-14180$.

Rossion, B., \& Gauthier, I. (2002). How does the brain process upright and inverted faces? Behavioral and Cognitive Neuroscience Reviews, 1(1), 63-75.

Shiffrar, M., \& Freyd, J. J. (1990). Apparent motion of the human body. Psychological Science, 1(4), 257-264.

Shiffrar, M., \& Freyd, J. J. (1993). Timing and apparent motion path choice with human body photographs. Psychological Science, 4(6), 379-384.

Slaughter, V., Heron, M., Jenkins, L., Tilse, E., Müller, U., \& Liebermann, D. (2004). Origins and early development of human body knowledge. Monographs of the Society for Research in Child Development, $i-113$.

Susilo, T., Yovel, G., Barton, J. J., \& Duchaine, B. (2013). Face perception is categoryspecific: Evidence from normal body perception in acquired prosopagnosia. Cognition, 129(1), 88-94.

Tanaka, J., \& Gauthier, I. (1997). Expertise in object and face recognition. Psychology of Learning and Motivation, 36, 83-125.

Yin, R. K. (1969). Looking at upside down faces. Journal of Experimental Psychology, 81(1), 141-145.

Zago, M., McIntyre, J., Senot, P., \& Lacquaniti, F. (2008). Internal models and prediction of visual gravitational motion. Vision Research, 48(14), 1532-1538.

Zhou, G., Zhang, L., Liu, J., Yang, J., \& Qu, Z. (2010). Specificity of face processing without awareness. Consciousness and Cognition, 19(1), 408-412. 